\title{
Financial requirements for the treatment of diabetes in Latin America: implications for the health system and for patients in Mexico
}

\author{
A. Arredondo • E. de Icaza
}

Received: 1 May 2009 / Accepted: 6 May 2009 / Published online: 6 June 2009

(C) Springer-Verlag 2009

Keywords Diabetes care - Financial requirements · Implications

To the Editor: Diabetes is a health problem that requires an integrated approach. The increasing incidence of diabetes has not been slowed by enhanced effort in providing treatments or by providing the economic resources necessary for these treatments. It is thought that the increase in the incidence of diabetes will continue. In Mexico, the prevalence of diabetes mellitus increased from $4.6 \%$ in 1993 to $22.8 \%$ in 2006 [1]. The impact of this disease is evident not only in mortality, but also in morbidity. This morbidity represents an enormous burden for individuals and their families, as well as for the health system and society in general [2].

The observed and forecast epidemiological changes in the incidence of diabetes will generate an increase in the need for health services [3]. The increasing costs of medical care, the unknown costs of the management of ambulatory and hospital cases, as well as the unknown economic resources needed to satisfy the future demands of health services, justify the development and implementation of indicators-urgently and in a focused way-for the increasing changes in demand and the costs of case management in the future.

The results presented here (Table 1) complement other results published in 2007 [4] that originated from a study of

\footnotetext{
A. Arredondo $(\square) \cdot$ E. de Icaza

National Institute of Public Health,

Av Universidad 655, Col Sta Maria,

Cuernavaca, Morelos, CP 62508, Mexico

e-mail: aarredon@insp.mx
}

annual monitoring of the costs and the financial consequences of the epidemiological changes in chronic degenerative diseases in Mexico. The estimated models of prognosis of demand refer to the period 2009-2011. The estimation method was based on the Box-Jenkins methodology [5] for health forecasts. For the estimations of the direct and indirect costs of diabetes, we took 2010 as a cutoff year, since it corresponds to half of the projected period of time. The estimates were made by consensus with clinical experts in the management of diabetes in different areas of the health sector. The direct costs of case management were determined from the functions of production, the combination of inputs, the standards of quality and the costs of the inputs for each sector. The indirect costs were determined using the human capital model developed for Latin America [5].

Comparing the economic impact in 2009 with the forecast for $2011(p<0.05)$, there is projected to be a $33 \%$ increase in financial requirements. The total cost for diabetes in 2010 is forecast to be US\$778,427,475 (see Table 1). This includes $\$ 343,226,541$ in direct costs and $\$ 435,200,934$ in indirect costs. The expected total direct costs are: $\$ 40,787,547$ for the Ministry of Health, serving the uninsured population; $\$ 113,664,454$ for the insured population (the Mexican Institute for Social Security, and the Institute for Social Security and Services for State Workers); $\$ 178,477,754$ for other healthcare service providers; and \$10,296,786 for private health insurance.

Diabetic nephropathy is the largest single contributor to the total cost of overall management. This is followed by the costs of treating retinopathy, cardiovascular disease, diabetic neuropathy and, with the least cost, peripheral vascular disease. 
Table 1 Direct, indirect and total costs (in US\$) for healthcare service providers attributable to diabetes expected for the year 2010 in Mexico

\begin{tabular}{|c|c|c|c|c|c|c|}
\hline \multirow[t]{2}{*}{ Costs } & \multicolumn{5}{|c|}{ Healthcare service provider } & \multirow[t]{2}{*}{ Total } \\
\hline & SSA & IMSS & ISSSTE & Other providers & PHI & \\
\hline \multicolumn{7}{|l|}{ Direct costs (US\$) } \\
\hline Consultations/diagnosis & $7,101,113$ & $16,029,089$ & $3,750,300$ & $31,061,914$ & $1,792,032$ & $59,734,448$ \\
\hline Drugs & $15,813,331$ & $35,749,875$ & $8,351,475$ & $69,234,743$ & $3,994,310$ & $133,143,734$ \\
\hline Hospitalisation & $4,747,670$ & $10,716,748$ & $2,507,381$ & $20,767,414$ & $1,198,118$ & $39,937,331$ \\
\hline Retinopathy & $1,443,797$ & $3,259,033$ & 762,510 & $4,593,095$ & 264,986 & $10,323,421$ \\
\hline Cardiovascular disease & $1,312,545$ & $2,962,757$ & 66,191 & $8,037,915$ & 463,726 & $12,843,134$ \\
\hline Nephropathy & $9,581,565$ & $21,628,130$ & $5,060,299$ & $43,060,262$ & $2,484,244$ & $81,814,501$ \\
\hline Neuropathy & 472,515 & $1,066,592$ & 249,548 & 918,619 & 52,997 & $2,760,271$ \\
\hline $\begin{array}{l}\text { Peripheral vascular } \\
\text { disease }\end{array}$ & 315,010 & 711,061 & 166,365 & 803,792 & 46,373 & $2,042,601$ \\
\hline Total direct & $40,787,547$ & $92,123,384$ & $21,541,070$ & $178,477,754$ & $10,296,786$ & $343,226,541$ \\
\hline \multicolumn{7}{|l|}{ Indirect costs (US\$) } \\
\hline Mortality & $2,267,624$ & $5,326,703$ & $1,217,070$ & $10,811,632$ & na & $19,623,029$ \\
\hline Permanent disability & $47,188,661$ & $110,847,272$ & $25,326,919$ & $225,842,994$ & na & $409,205,846$ \\
\hline Temporary disability & 712,395 & $1,673,432$ & 382,353 & $3,603,879$ & na & $6,372,059$ \\
\hline Total indirect & $50,168,680$ & $117,847,407$ & $26,926,342$ & $240,258,505$ & na & $435,200,934$ \\
\hline Total costs* & $90,956,227$ & $209,970,791$ & $48,467,412$ & $418,736,259$ & $10,296,786$ & $778,427,475$ \\
\hline
\end{tabular}

Source: A. Arredondo, E. de Icaza, R. Ramos, A. Zuñiga and C. Carrillo, unpublished results

Exchange rate: January 2009, 1 US $\$=13.35$ Mexican $\$$

${ }^{*} p<0.05$ (Box-Pierce statistical test) for the difference in expected total costs in 2010 between the different institutions (i.e. SSA, IMSS, ISSSTE, Other providers, PHI)

IMSS, Mexican Institute for Social Security; ISSSTE, Institute for Social Security and Services for State Workers; na, not available; PHI, private health insurance; SSA, Ministry of Health

In relation to the effects of the observed epidemiological changes in healthcare demand for hospitalised and ambulatory services for 2009-2011, it is expected that there will be a tendency for an increase in the costs, although the increase is greater for the insured population than the uninsured population.

With regard to direct costs to patients, the high relative expense of diabetes treatment paid for from family income and its implications for equity and access to healthcare in Mexico are noteworthy. Indeed, for every $\$ 100$ spent on diabetes in Mexico, approximately $\$ 51$ comes from the home/family income. This represents a heavy social burden that will have a considerable effect on the health expenditure of the country, because diabetes is a very expensive disease to treat and has a high priority as a public health problem. Although these indirect costs do not constitute a direct impact on the health budget, they do represent a burden that society in general will have to assume - mainly in terms of lost productivity by premature death and temporary or permanent disability. The estimated financial requirements constitute the fundamental basis of data for strategic planning. Indeed, given the financial consequences of the expected epidemiological changes, it essential to invest greater financial resources. It also justifies the implementation of health prevention strategies.

With regard to the implications for the health system and for patients, we propose the following:

1. The evidence for projected changes in costs and in the demand for healthcare for diabetes patients can be used as a reference for the allocation of resources directed towards diabetes by different types of public institutions. With a knowledge of probable financial requirements, each institution could target the necessary resources for promotion, prevention, healing and rehabilitation effectively and efficiently.

2. A consequence of the implementation of costmonitoring systems is the design and application of strategies for cost-containment for weight-by-cost items. For example, knowing that the cost of medicines is high, it will be necessary for each institution to review its agreements with the pharmaceutical industry on the consolidated purchase of medicines for diabetes.

3. Development of economic indicators would enable the design of patterns of resource allocation based on efficiency criteria with regard to clinical, epidemiolog- 
ical, economic and administrative aspects. Each institution could develop models for the distribution of resources in accordance with the changes in projected costs and epidemiological factors.

4. As a 'Citizen Observatory of Diabetes', social organisations could develop follow-up programmes for the costs of diabetes in different public and private health institutions. The Observatory could function as a checking system that would monitor how much was being spent on managing diabetes and what the money was being spent on.

5. Knowledge of the relative cost of the management of diabetes based on annual family income, as well as precise knowledge of the cost of complications to the users, should be made available through bulletins sent to diabetic patients and their relatives, and to the community as a whole. This should lead to greater selfawareness and effort in avoiding complications caused by diabetes.

6. A list of recommendations is needed to promote greater self-care and control of risk factors, emphasising the financial benefits of this approach. This could help patients to avoid economic hardship (i.e. $>30 \%$ of the family income spent on diabetes) because of diabetes.

Within the field of health services, and research and development in human resources, our results suggest that there should be a greater emphasis on health evaluation and promotion, with important changes in the social aspects of diabetes being a high-priority public health problem. The treatment of diabetes should be approached from an integrated perspective: clinical, economic, epidemiological and organisational. In other words, an integrated approach to the problem of diabetes requires the development of indicators of clinical and economic efficiency, expected epidemiological changes and demands for medical attention and services.

Acknowledgements The authors would like to acknowledge the National Council for Science and Technology (Mexico) and the International Development Research Centre (Canada) for funding.

Duality of interest The authors declare that there is no duality of interest associated with this manuscript.

\section{References}

1. National Institute of Public Health (2009) Métodos de estimación de cambios epidemiológicos y demanda esperada de enfermedades crónico-degenerativas. Informe Técnico de Memoria Metodológica, Cuernavaca, México, pp 63-78

2. Brown JB, Pedula KL, Bakst AW (1999) The progressive cost of complications in type 2 diabetes mellitus. Arch Intern Med 159:1873-1880

3. International Diabetes Federation (1999) Direct cost to the health care sector. Diabetes health economics. International Diabetes Federation, Brussels, Belgium, pp 29-35

4. Arredondo A, Barceló A (2007) The economic burden of out-ofpocket medical expenditures for patients seeking diabetes care in Mexico. Diabetologia 50:435-436

5. Barcelo A, Aedo C, Rajpathak S, Robles S (2003) The cost of diabetes in Latin America and the Caribbean. Bull World Health Organ 81:19-27 